EdCW 2020

International Scientific and Practical Conference Education in a Changing World: Global Challenges and National Priorities

\title{
THE USE OF INFORMATION TECHNOLOGIES IN FITNESS ACTIVITIES UNDER THE COVID-19 RESTRICTIONS
}

\author{
Yulia Lyakh (a)*, Alexey Ermakov (b), Elena Sarafanova (c) \\ *Corresponding author
}

(a) Moscow Psychologic-Social University, Moscow, Russia, pani.lyah@gmail.com

(b) Russian State University of Physical Education, Sport, Youth and Tourism (SCOLIPE), Moscow, Russia, Federal Scientific Center of Physical Culture and Sports, Moscow, Russia, bigbr@mail.ru

(c) Competence center "Manpower for digital economy", Moscow, Russia, S5286@mail.ru

\begin{abstract}
The study is devoted to the organization of independent physical education and sports by the population in the context of the restrictions that arose in connection with the COVID-19 pandemic. The issues of the development of the information society and the forms and types of physical culture activities, sports and fitness are considered in detail, but there are no works providing data on physical culture, sports and fitness in the information society. The article discusses the problem of the population's readiness to use information technologies for physical education, sports and fitness immediately before the onset and during the restrictions associated with the COVID-19 pandemic. It was concluded that during the onset of the restrictions associated with the COVID-19 pandemic, a significant part of the population was not ready to organize independent physical education exercise sessions and sports activities using digital technologies. Gender preferences were revealed, thus, women significantly more often practiced exercises for flexibility and coordination. Men were more likely to have a passion for strength exercises. The use of digital technologies was recorded at an insufficient level. There were some gender specificities. Women more often practiced online classes with a trainer, and men used digital technologies (Just Dance, VR, AR, etc.), but no significant differences were found.
\end{abstract}




\section{Introduction}

Our research is devoted to the development of the information society, the combination of elements of the industrial and information (post-industrial) society in general and specifically to the organization by the population of independent physical culture and sports activities under the conditions of restrictions arising due to the COVID-19 pandemic. The situation associated with the spread of the disease significantly limited the population's ability to organize any group exercise and a large number of habitual forms and types of physical activity. The use of digital technologies could partially replace traditional activities, and perhaps a faster implementation of certain features of the information society in the everyday life of the population of Russia and its nearest neighbours could take place.

To consider the place and prevalence of the use of digital technologies by the population when organizing the population of independent physical education and sports in the period immediately preceding and during the restrictions that arose in connection with the COVID-19 pandemic, we conducted a two-stage study, in which a large number of respondents from different countries took part. This study was a logical continuation of our study on the peculiarities of the motor activity of the population of Russia (Ermakov, 2020b) and a study on the peculiarities of the psychophysical activity of a person in the information society (Ermakov, 2020a).

\section{Problem Statement}

The problem of the formation of the information society has long been a debated topic in the international scientific community (Webster, 2014). Some authors talk about the practically forced information society in certain countries, such as, for example, Japan (Masuda, 1980). Most experts, trying to determine the features of a new society, come to the conclusion that the accuracy of forecasts for its development is rather low, and we can only talk about the most noticeable trends. A separate promising area of research can be the link between the information society and the networked society (Lyon, 2013).

Despite the significant development of the topic of the information society, the topic of organizing physical culture and sports activities of the population remains underexplored. When the authors place physical culture and sports in a modern social context, they often talk about the influence of politics, the marginalization of society (Bailey, 2018). Even in contemporary writings, the theme of the information society is being replaced by the need to implement "Olympic education" (Kohe et al., 2021). Moreover, some authors seek to expand this social phenomenon to the maximum number of forms and types of physical activity of the population (Ribeiro et al., 2020).

Only individual works are devoted to the physical activity of a person in a new society, but the issues considered in them do not allow us to declare the full disclosure of the topic. For example, there are works devoted to maintaining health by means of physical culture and sports in a sedentary lifestyle in the information society (Mokmin \& Jamiat, 2020). Some, raising the questions of the population's physical activity throughout the entire period of life, that interest us, do not directly include digital technologies as part of the information society (Malina, 1996). At the same time, digital technologies are now actively used to determine the skill level of specialists in the field of physical culture, sports and fitness according to Worldskills standards (Ermakov et al., 2020). Some of the small number of works 
that affect the topic of interest to us are the works by Skarzhinskaya ana Sarafanova (2020), Strelnikova and Novoselov (2018). It should also be added that, in addition to technological solutions, ethical problems of the development of sports in the digital space are becoming important (Skarzhinskaya, 2020). At the same time, the physical activity of the population is considered as a significant factor for the development of the economy (Zyurin et al., 2020). Thus, the readiness of the population to use digital technologies is becoming a significant factor in organizing physical education, sports and fitness activities.

\section{Research Questions}

3.1. What peculiarities of the use of digital technologies in organizing the population's independent physical education and sports activities were observed in the period immediately preceding the restrictions associated with the COVID-19 pandemic?

3.2. How high was the readiness of the population to organize independent physical education and sports activities using various digital technologies?

3.3. What features of the use of digital technologies in organizing the population's independent physical education and sports activities were observed during the period of the restrictions associated with the COVID-19 pandemic?

\section{Purpose of the Study}

The purpose of the study is to study the organization of independent physical culture and sports activities by the population and the place of digital technologies in it, by comparing with the data preceding the restrictions.

\section{Research Methods}

The research took place in two stages, each of which was characterized by its own methodological approach, goals and objectives.

At the first stage, the research results were obtained from the analysis of the ONETRAK company's database. This database analyzed the physical activity of the Russian population in the period immediately preceding the restrictions associated with the COVID-19 pandemic, and also considered the gender and age characteristics of the use of wearable gadgets, as an example of the use of digital technologies in organizing the physical activity of the population. The survey involved 40145 respondents, of which 37072 respondents were selected, the data on which corresponded to the quality required for the study and were complete. The survey took place from September 2018 through September 2019. The geography of the study covered 951 settlements in Russia (which amounted to $85.14 \%$ of all cities in Russia).

At the second stage, a public survey was conducted on vk.com social network at the end of April 2020 (Figure 01). At this stage, according to the polls of respondents (1.754 people took part in the 
survey), the peculiarities of the organization of physical activity of the population were determined in the context of the restrictions imposed related to the COVID-19 pandemic. It was proposed to attribute the ways of organizing one's own motor activity to those selected from the nine proposed ones or to determine one's own, which was not included in the list. Each respondent could choose from one to three options most suitable for them. The geography of the study included respondents from Russia, Ukraine, Belarus and Kazakhstan.

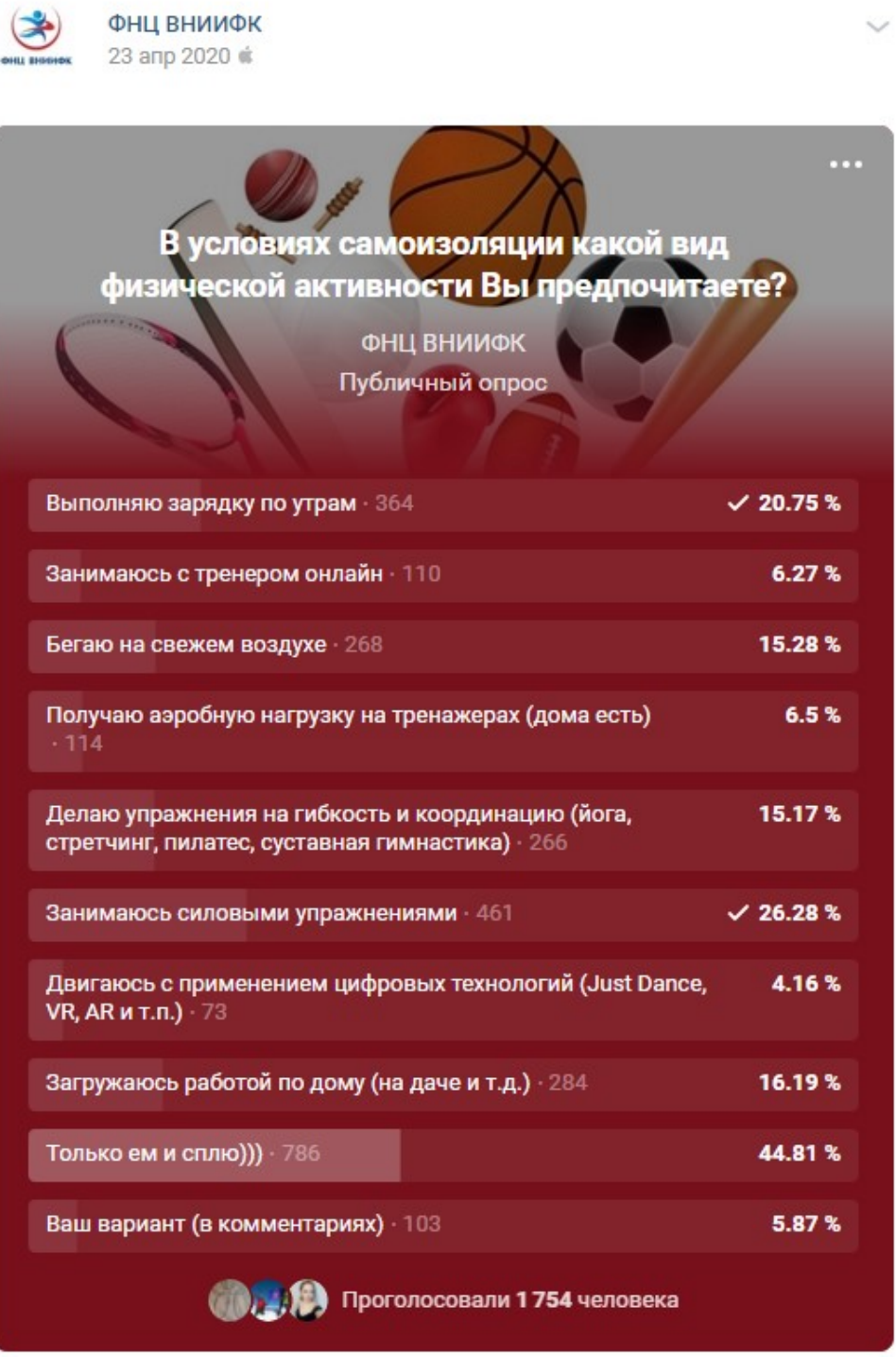

Figure 1. Page of the survey conducted in the vk.com social network

[«FSCARSRIPCSApril $23^{\text {rd }} 2020$

In self-isolation, what kind of physical activity do you prefer?

\section{FSCARSRIPCS}

Public poll

I exercise in the morning $\cdot 364$

I work out with a trainer online 110 
I go for runs in the fresh air 268

I get aerobic exercise on fitness machines (I have them at home) $1146.5 \%$

I do exercises for flexibility and coordination

(yoga, stretching, pilates, joint gymnastics) 266

I do strength training 461

I work out using digital technology

(Just Dance, VR, AR, etc) 73

I am loaded with chores (in the country, etc.) 284

All I do is eat and sleep :) 786

\section{4 persons voted»]}

\section{Findings}

During the first stage of the study (when the population could already use information technologies to organize their own physical activity, but significant additional prerequisites for this, in addition to the development of the technologies themselves and an increase in their availability, have not yet been observed), it was found that technologies (in this case, wearable gadgets) are used unevenly by different groups of the population (by gender and age). A clear distribution of respondents by gender is shown in Figure 02.

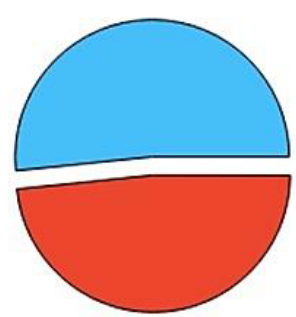

under 16

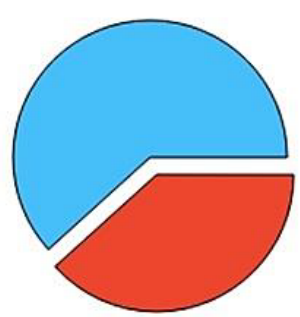

from 16 to 27 years old

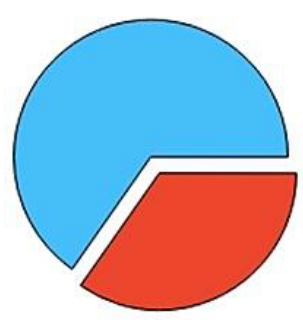

from 28 to 45 years old

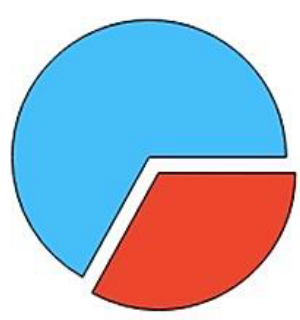

over 45 years old

$$
\begin{aligned}
& \square \text { female } \\
& \text { male }
\end{aligned}
$$

Figure 2. Distribution of respondents by gender in the study of the use of wearable gadgets by the population

It can be seen that there is a difference between the use of wearable gadgets among female and male respondents, depending on age. If among respondents under the age of 16 it is insignificant, then, with increasing age, the prevalence of women who use wearable gadgets to control their own physical activity becomes obvious. This unevenness may indicate that the society has not finally formed a willingness to use digital technologies (for example, wearable gadgets) to control and organize their own physical activity. 
Despite the apparent difference, the analysis of the data carried out using the Orange 3 software showed that the differences, although they exist, are in the zone of uncertainty and conclusions should be drawn with sufficient caution (Figure 03).

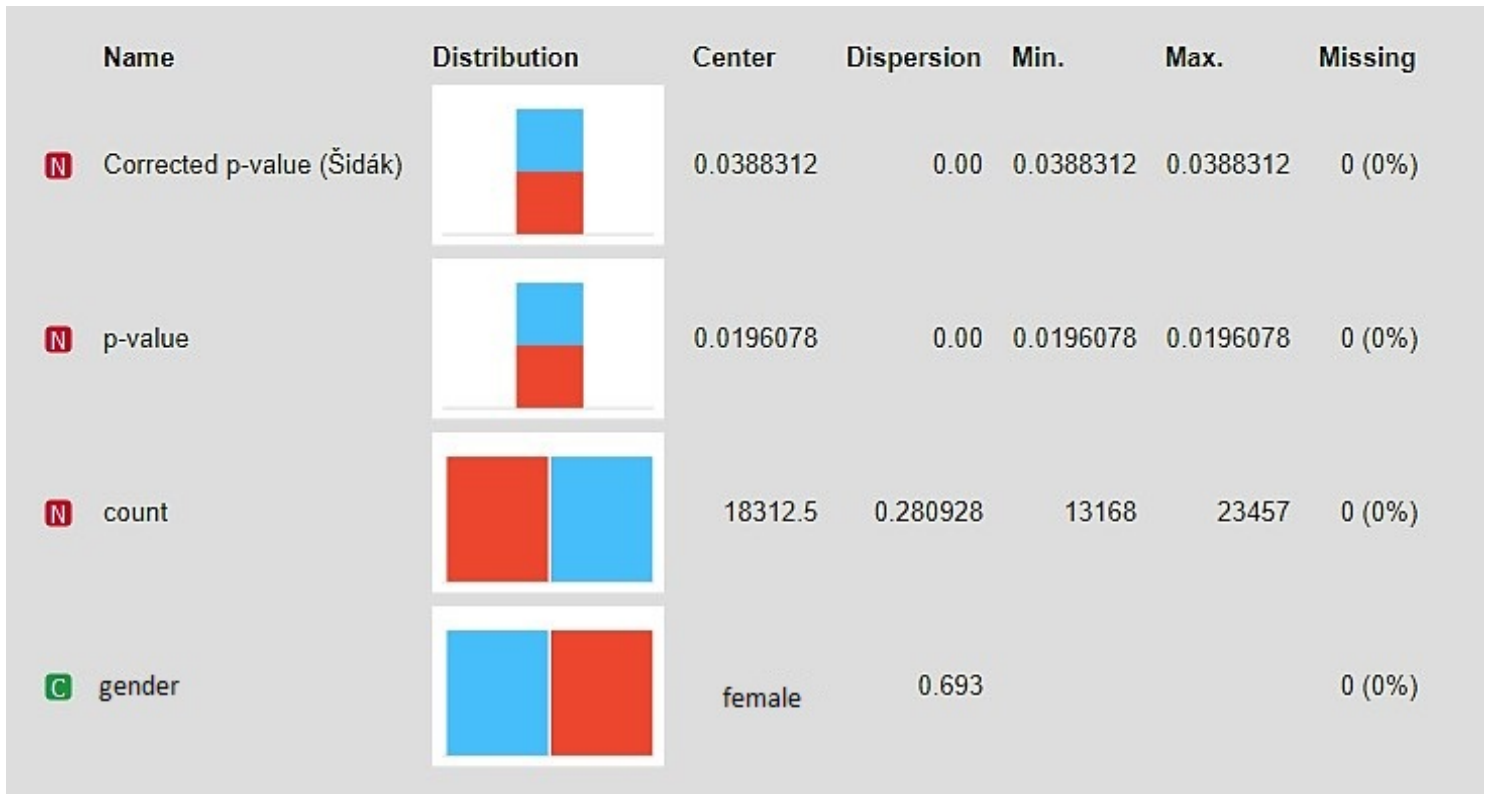

Figure 3. Data analysis of the first part of the study using Orange 3 software

The second part of our study was conducted at the end of April 2020, which allowed us to draw conclusions about the readiness of the population to use digital technologies for organizing their own physical activity (physical culture and sports) with restrictions for this implementation in traditional ways. A summary of the study is presented in Table 01 .

Table 1. Summary results of a survey conducted in the vk.com social network

\begin{tabular}{lcc}
\hline \multicolumn{1}{c}{ Activities } & Number of votes & $\%$ \\
\hline All I do is eat and sleep & 786 votes & $44.81 \%$ \\
I do strength training & 461 votes & $26.28 \%$ \\
I exercise in the morning & 364 votes & $20.75 \%$ \\
I am loaded with chores (in the country, etc.) & 284 votes & $16.19 \%$ \\
I go for runs in the fresh air & 286 votes & $15.28 \%$ \\
I do exercises for flexibility and coordination (yoga, stretching, pilates, & 266 votes & $15.17 \%$ \\
joint gymnastics) & 114 votes & $6.5 \%$ \\
I get aerobic exercise on fitness machines (I have them at home) & 110 votes & $6.27 \%$ \\
I work out with a trainer online & 103 votes & $5.87 \%$ \\
Your option (in the comments) & 73 votes & $4.16 \%$ \\
I work out using digital technology (Just Dance, VR, AR, etc.) & 1754 people \\
Total & \multicolumn{2}{c}{10.04} \\
\hline
\end{tabular}

Considering the data obtained, one can draw attention to the fact that a significant part of the respondents (44.81\%) was not ready to independently organize physical culture and sports activities. Others used the traditional approaches of the industrial society practiced throughout the twentieth century (running, morning exercises, strength exercises, flexibility exercises, etc.) for this. A small number of 
respondents (16.19\%) consciously chose chores as physical activity. The values of the use of home cardio simulators turned out to be relatively low, which can serve as an indirect indicator of the psychological restriction of a part of the population towards an "indirect" physical education and sports activities, in which an additional, relatively complex technical device is used.

The readiness of the population to use digital tools for organizing physical culture and sports activities turned out to be the lowest. A small number of respondents (6.27\%) used the Internet to contact a trainer and least of all (4.16\%) used devices that can be characterized as "digital inventory".

Considering the data in more detail, it is possible to distinguish various clusters in them by gender, age and territorial affiliation. Gender differences are presented in Table 02.

Table 2. Gender characteristics of the organization of physical culture and sports activities in the context of the COVID-19 pandemic

\begin{tabular}{lllll}
\hline \multicolumn{1}{c}{ Activity } & \multicolumn{2}{c}{ Male } & \multicolumn{2}{c}{ Female } \\
\hline All I do is eat and sleep & 503 votes & $47.9 \%$ & 283 votes & $40.2 \%$ \\
I do strength training & 325 votes & $30.95 \%$ & 136 votes & $19.32 \%$ \\
I exercise in the morning & 197 votes & $18.76 \%$ & 167 votes & $23.72 \%$ \\
I am loaded with chores (in the country, etc.) & 148 votes & $14.1 \%$ & 136 votes & $19.32 \%$ \\
I go for runs in the fresh air & 173 votes & $16.48 \%$ & 95 votes & $13.49 \%$ \\
I do exercises for flexibility and coordination (yoga, & 89 votes & $8.48 \%$ & 177 votes & $25.14 \%$ \\
stretching, pilates, joint gymnastics) & & & & \\
I get aerobic exercise on fitness machines (I have them at & 79 votes & $7.52 \%$ & 35 votes & $4.97 \%$ \\
home) & 59 votes & $5.62 \%$ & 51 votes & $7.24 \%$ \\
I work out with a trainer online & 73 votes & $6.95 \%$ & 30 votes & $4.26 \%$ \\
Your option (in the comments) & 51 votes & $4.86 \%$ & 22 votes & $3.13 \%$ \\
I work out using digital technology (Just Dance, VR, AR, & & & \\
etc.) & 1050 people & 704 people \\
Total & & & \\
\hline
\end{tabular}

When considering gender characteristics, the main one can be distinguished, women preferred exercises for flexibility and coordination more compared to men ( $25.14 \%$ and $8.48 \%$, respectively). Men preferred strength exercises more than women (30.95\% and $19.32 \%$, respectively). The rest of the comparisons were not so significant. Despite the insignificance, we are interested in data on the use of technical devices, both traditional (cardio simulators) and information technologies. Thus, men slightly more than women use cardiovascular equipment (7.52\% and 4.97\%, respectively) and digital technologies (Just Dance, VR, AR, etc.)(7.24\% and 4.86\%, respectively). Women, however, were slightly more likely than men to practice online classes with a trainer $(5.62 \%$ and $3.13 \%$, respectively). When comparing these data with the data of the first part of the study, it can be assumed that there are insignificant gender preferences in the use of digital technologies for independent physical education and sports activities.

Age peculiarities of the organization of independent physical culture and sports activities are presented in Table 03. 
Table 3. Age peculiarities of the organization of independent physical education and sports activities in the context of the COVID-19 pandemic

\begin{tabular}{lcccc}
\hline \multicolumn{1}{c}{ Activity } & \multicolumn{2}{c}{17 to 35 years old } & \multicolumn{2}{c}{ over 35 years old } \\
\hline All I do is eat and sleep & 361 votes & $42.03 \%$ & 80 votes & $31.13 \%$ \\
I do strength training & 209 votes & $24.33 \%$ & 63 votes & $24.51 \%$ \\
I exercise in the morning & 170 votes & $19.79 \%$ & 58 votes & $22.57 \%$ \\
I am loaded with chores (in the country, etc.) & 151 votes & $17.58 \%$ & 47 votes & $18.29 \%$ \\
I go for runs in the fresh air & 116 votes & $13.5 \%$ & 35 votes & $13.62 \%$ \\
I do exercises for flexibility and coordination (yoga, & 143 votes & $16.65 \%$ & 37 votes & $14.4 \%$ \\
stretching, pilates, joint gymnastics) & & & \\
I get aerobic exercise on fitness machines (I have them at & 53 votes & $6.17 \%$ & 19 votes & $7.39 \%$ \\
home) & & & & \\
I work out with a trainer online & 43 votes & $5.01 \%$ & 16 votes & $6.23 \%$ \\
Your option (in the comments) & 37 votes & $4.31 \%$ & 12 votes & $4.67 \%$ \\
I work out using digital technology (Just Dance, VR, AR,, & 29 votes & $3.38 \%$ & 6 votes & $2.33 \%$ \\
etc.) & \multicolumn{2}{c}{859 people } & 257 people \\
Total & & & \\
\hline
\end{tabular}

In considering the age characteristics of the organization of independent physical culture and sports activities, one can single out only a slightly greater organization of respondents over 35 years old. The first position of the poll "All I do is eat and sleep", showing a passive attitude to physical culture and sports activities among young people, was more often chosen in comparison with older age $(42.03 \%$ and $31.13 \%$, respectively).

The data, clustered by territorial affiliation, did not reveal significant differences between citizens of different states (Russia, Ukraine, Belarus and Kazakhstan).

\section{Conclusion}

To summarize, one can say that in the period immediately preceding the restrictions associated with the COVID-19 pandemic, there were gender-age peculiarities of the use of digital technologies (for example, wearable gadgets). Among respondents under 16, the differences are insignificant, but in other age groups, women more often than men used gadgets.

During the onset of the restrictions related to the COVID-19 pandemic, a significant part of the population was not ready to organize independent physical education and sports activities using digital technologies. A large number of respondents were passive and did not devote enough time to physical activity. Those who went in for physical culture and sports on their own preferred traditional forms and types of activity inherent in an industrial society. Gender preferences were revealed, thus, women significantly more often practiced exercises for flexibility and coordination. Men were more likely to have a passion for strength exercises.

The use of digital technologies was recorded at an insufficient level. There were some gender specificities. Women more often practiced online classes with a trainer, and men used digital technologies (Just Dance, VR, AR, etc.), but no significant differences were found. 


\section{References}

Bailey, R. (2018). Sport, physical education and educational worth. Educational Review, 70(1), 51-66. https://doi.org/10.1080/00131911.2018.1403208

Ermakov, A. (2020a). Potential of deconcentration of attention methods for use in the information society. BIO Web of Conferences, 26, 00067. https://doi.org/10.1051/bioconf/20202600067

Ermakov, A. V. (2020b). Rezultaty monitoring dvigatelnoj aktivnosti naseleniya s ispolzovaniem analiza "bolshih dannyh" kompanii Onetrak. [Results of monitoring the physical activity of the population using the Big Data analysis of the Onetrak company]. Sportivno-pedagogicheskoe obrazovanie: setevoe izdanie [Sports and pedagogical education: online edition], 2, 18-22.

Ermakov, A. V., Oblog, K. A., Shchegoleva, A. P., \& Ziborova, S. A. (2020). Ocenka intensivnosti fizicheskoj nagruzki v demonstracionnom ekzamene po kompetencii "Fizicheskaya kul'tura, sport i fitness" po standartam Worldskills Russia pri pomoshchi umnyh brasletov ONETRAK C 320 Pulse. [Assessment of the intensity of physical activity in the demonstration exam in the competence "Physical culture, sports and fitness" according to Worldskills Russia standards using smart bracelets ONETRAK C 320 Pulse]. Vestnik sportivnoj nauki [Bulletin of Sports Science], 4, 74-78.

Kohe, G. Z., Aramaki, A., Sekine, M., Masumoto, N., \& Hsu, L. (2021). Conceptualising l'space olympique: Tokyo 2020 Olympic education in thought, production and action. Educational Review. Published online: 05 Feb 2021. https://doi.org/10.1080/00131911.2021.1874308

Lyon, D. (2013). The information society: Issues and illusions. John Wiley \& Sons.

Malina, R. (1996). Tracking of physical activity and physical fitness across the lifespan. Research Quarterly for Exercise and Sport, 67(3), 48-57. https://doi.org/10.1080/02701367.1996.10608853

Masuda, Y. (1980). The information society: As post-industrial society. World Future Society.

Mokmin, N. A. M., \& Jamiat, N. (2020). The effectiveness of a virtual fitness trainer app in motivating and engaging students for fitness activity by applying motor learning theory. Education and Information Technologies, 1, 18.https://doi.org/10.1007/s10639-020-10337-7

Ribeiro, T., Correia, A., Figueiredo, C., \& Biscaia, R. (2020). The Olympic Games' impact on the development of teachers: the case of Rio 2016 Official Olympic Education Programme. Educational Review, 1-20. https://doi.org/10.1080/00131911.2020.1837739

Skarzhinskaya, E. N. (2020). Eticheskie problemy sporta v cifrovom prostranstve [Ethical issues of sports in the digital space]. In V. V. Kortunov (Ed.) Socialnye smysly sportivnoj duhovnosti [Social Meanings of Sports Spirituality] (pp. 127-129). Armavir State Pedagogical University.

Skarzhinskaya, E. N., \& Sarafanova, E. V. (2020). Digital technologies in physical culture and sports education. Advances in Economics, Business and Management Research, 11, 805-807. https://doi.org/10.2991/aebmr.k.200114.194

Strelnikova, G. V., \& Novoselov, M. A. (2018). Vliyanie zanyatij fizicheskoj kulturoj s ispolzovaniem kibersportivnogo simulyatora just dance na koordinacionnye sposobnosti shkolnikov [The influence of physical education classes using the just dance cybersport simulator on the coordination abilities of schoolchildren]. Teoriya i praktika fizicheskoj kultury [Theory and practice of physical culture], 8, 102-103.

Webster, F. (2014). Theories of the information society. Routledge. https://doi.org/10.4324/9781315867854

Zyurin, E. A., Petruk, E. N., \& Bobkova, E. N. (2020). Nauchnoe obosnovanie dvigatel'nogo rezhima ekonomicheski aktivnogo naseleniya Rossijskoj Federacii [Scientific substantiation of the motor regime of the economically active population of the Russian Federation]. In L. A. Zaks (Ed.), Publichnoe/chastnoe v sovremennoj civilizacii [Public/Private in Modern Civilization] (pp. 714719). Autonomous Non-profit Higher Education Organization "Humanitarian University". 